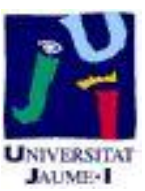

Título artículo / Títol article: Education modulates the association of the FTO rs9939609 polymorphism with body mass index and obesity risk in the Mediterranean population

Autores / Autors

Corella, Dolores ; Carrasco, Paula ; Sorlí, J. V. ;

Coltell Simón, Oscar ; Ortega Azorín, Carolina ;

Guillen, Montserrat ; González, José I. ; Sáiz,

Carmen ; Estruch Riba, Ramon ; Ordovás, José M.

Revista:

Nutrition, Metabolism and Cardiovascular Diseases

(2012) 22 (8)

Versión / Versió:

Cita bibliográfica / Cita bibliogràfica (ISO 690):
Post-print

CORELLA, D., et al. Education modulates the association of the FTO rs9939609 polymorphism with body mass index and obesity risk in the Mediterranean population. Nutrition, Metabolism and Cardiovascular Diseases, 2012, vol. 22, no 8, p. 651658.

url Repositori UJI:

http://hdl.handle.net/10234/69440 


\title{
Education modulates the association of the FTO rs9939609 polymorphism with body mass index and obesity risk in the Mediterranean population
}

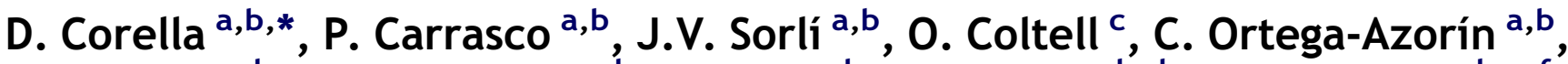 \\ M. Guillén ${ }^{a, b}$, J.I. González ${ }^{a, b}$, C. Sáiz ${ }^{a, b}$, R. Estruch ${ }^{\text {b,d }}$, J.M. Ordovas ${ }^{b, e, f}$
}

${ }^{a}$ Genetic and Molecular Epidemiology Unit, School of Medicine, University of Valencia, Blasco Ibañez, 15, 46010 Valencia, Spain

${ }^{\mathrm{b}}$ CIBER Fisiopatología de la Obesidad y Nutrición, Instituto de Salud Carlos III, Madrid, Spain

' Department of Computer Languages and Systems, University Jaume I, Castellón, Spain

'Department of Internal Medicine, Hospital Clinic, Barcelona, Spain

e Nutrition and Genomics Laboratory, JM-USDA Human Nutrition Research Center on Aging at Tufts University, Boston, MA, USA

f Department of Cardiovascular Epidemiology and Population Genetics, Centro Nacional de Investigaciones

Cardiovasculares (CNIC), Madrid, Spain

Received 24 July 2010; received in revised form 16 October 2010; accepted 18 October 2010

\section{KEYWORDS}

Obesity;

FTO;

Educational level;

Physical activity;

Mediterranean

\begin{abstract}
Objective: To define whether the rs9939609 FTO (fat mass and obesity associated) single nucleotide polymorphism (SNP) is associated with anthropometric measurements and its modulation by educational level in a Mediterranean population.

Methods: We studied 3 independent adult samples: a random sample $(n=1580)$ from the general population (GP), obese hospital patients (OHP) $(n=203)$ and elderly subjects $(n=1027)$ with high cardiovascular risk (HCR). Weight and height were directly measured. Education and physical activity (PA) were measured using questionnaires.

Results: The rs9939609 presented heterogeneous associations with BMI. In the GP, the minor Aallele was significantly associated with greater $\mathrm{BMI}$, following a co-dominant pattern $(P=0.009)$, whereas in the OHP this association was recessive $(P=0.004)$. Conversely, we did not find a significant association with BMI in the HCR group $(P<0.596)$. In the GP we found a significant interaction between the FTO SNP and education $(P=0.048)$. In the stratified analysis, no association of the FTO SNP with greater BMI in university subjects was detected $(P=0.786)$, whereas the association was observed in non-university subjects $(P=0.001)$.
\end{abstract}

\footnotetext{
* Corresponding author. Genetic and Molecular Epidemiology Unit, School of Medicine, University of Valencia, Blasco Ibañez, 15, 46010 Valencia, Spain. Tel.: +34 963864417; fax: +34 963864166.

E-mail address: dolores.corella@uv.es (D. Corella).
} 
The FTO $\times$ education interaction $(P=0.020)$ was also observed in determining obesity risk in the GP. A-allele carriers had a greater risk of being obese only if they had no university education (OR: 1.56 ; $95 \% \mathrm{Cl}: 1.09-2.23$ for TA and OR: $2.01 ; 95 \% \mathrm{Cl}: 1.27-3.26$ for AA subjects). The interaction of the FTO with education remained significant even after adjustment for PA. Conclusions: The association of the FTO SNP with greater BMI and obesity risk in the GP was strongly modulated by education.

(c) 2010 Elsevier B.V. All rights reserved.

\section{Introduction}

Within the complex etiology of cardiovascular diseases and obesity, it has long been known that lower educational level is a shared risk factor [1-3]. Especially notable has been the recent increasing prevalence of obesity in subjects of lower educational level/socioeconomic status [4-7]. Although several studies have been carried out to investigate the differences in diet, exercise and other environmental variables among subjects with different educational level that may influence the risk of obesity [8-10], there have been very few studies that have investigated the genetic influence on the association between education and obesity-related variables, most of them being heritability studies conducted on twins $[11,12]$. Thus, a study undertaken on Danish twins [12], investigated how genetic and environmental variance in physical health differed with level of education, and concluded that education reduced the influence of genetic susceptibility to poor health, suggesting that this might take place because more educated people manage their environments better to protect their health. Concerning the analysis of specific loci, there is one study showing that a low educational level aggravated the association between the rs3809508 neuromedin $B$ single nucleotide polymorphism (SNP) and the risk of obesity in the HELENA study [13].

Genetic variation, namely the rs9939609 SNP, at the fat mass and obesity associated (FTO) gene has been frequently associated with common obesity [14-18]; however, not all the studies undertaken have found statistically significant associations between the FTO variant alleles and greater body mass index (BMI) [19-21]. Even in studies which have found significant associations between the rs9939609 and $\mathrm{BMI}$, differences have been detected in the magnitude of the association depending on the population analyzed [14-18,22-24]. These studies are done with different ethnical backgrounds as well as with different demographic characteristics. Among the demographic characteristics, some studies have suggested that the effect could be greater in children and adolescents and lesser in elderly people [22-24]. Among the environmental interactions that may modulate the association of the FTO SNP with BMI, physical activity (PA) has been the most commonly studied. Several studies have found that low PA accentuates the effects of FTO risk-allele, whereas, high PA attenuates the association of that allele with greater BMI [24-26]. Nevertheless, not all the studies have been able to observe that modulation $[27,28]$. Although PA has been related to education in some studies [29] [for example, participation in exercise and sports was positively associated with educational level in Eurobarometers [29]], there is no published study that has examined the interaction between the FTO gene variation and education in determining the risk of obesity.

Taking into account the diversity of effects of the FTO SNP on BMI depending on the characteristics of the population as well as the gap in knowledge regarding the modulation of this association by education status, our aims were: 1) To study the association between the FTO rs9939609 SNP and $\mathrm{BMI}$ in three independent samples of the same Mediterranean population that differ in socio-demographic and anthropometric characteristics in order to estimate the homogeneity/heterogeneity of the association; 2) To study the interaction of educational level on the association of the rs9939609 SNP with BMI and obesity in these samples.

\section{Methods}

\section{Subjects and study design}

We included Caucasian subjects from three independent Mediterranean samples 1580 subjects from the general population (GP), 203 severely obese patients from a hospital (OHP) and 1027 elderly subjects with high cardiovascular risk (HCR). All participants gave their informed consent. The ethics committee of the University of Valencia approved the studies.

\section{Subjects from the GP}

We studied 1580 unrelated subjects (757 men and 823 women) participating in a previous study (EPIGEM Study) aimed at ascertaining the prevalence of both genetic and environmental cardiovascular risk factors in this Mediterranean population [30]. Participants (aged 18-70 y; mean age: $41.2 \pm 13.8$ y) were apparently healthy, unrelated subjects residing or working in the Valencia region (East Mediterranean coast of Spain), recruited between 2000 and 2006.

\section{OHP}

We studied 203 unrelated obese patients (37 men and 166 women), aged $18-68$ y (mean age: $46.3 \pm 14.7$ y) referred to the Endocrinology Unit of the University General Hospital in Valencia (from May 2001 to June 2003), for diagnostic and weight reduction treatments related to obesity and who agreed to take part in the study, as previously described [31]. Prevalence of morbid obesity $\left(\mathrm{BMl}>=40 \mathrm{~kg} / \mathrm{m}^{2}\right.$ in this sample was $51 \%)$. 


\section{Elderly subjects with HCR}

1027 unrelated subjects ( 325 men and 582 women), aged $55-80$ y (mean age: $67.3 \pm 6.4 \mathrm{y}$ ) who participated in the PREDIMED (Prevención con Dieta Mediterránea) study and were consecutively recruited in the Valencia Region from October 2003 to December 2008 were included. Details of this study have been previously reported [32]. Briefly, participants were elderly community-dwelling persons who fulfilled at least 1 of 2 criteria: type 2 diabetes or 3 or more cardiovascular risk factors (current smoking, hypertension, dyslipidemia, overweight, or a family history of premature cardiovascular disease).

\section{Anthropometric and clinical determinations}

Anthropometric variables were directly measured by trained nurses in the three populations by standard techniques [30-32]. Height and weight were measured with light clothing and no shoes. Obesity was defined as $\mathrm{BMI}>=30 \mathrm{~kg} / \mathrm{m}^{2}$. Waist circumference was measured midway between the lowest rib and the iliac crest using an anthropometric tape. Fasting venous blood was collected.

\section{Education, physical activity and other lifestyle variables}

The same questionnaires were used for both the GP and $\mathrm{OHP}$, and data of demographic variables, education, and PA, were assessed as previously reported [30,31]. Questions on education were divided into 5 categories illiterate, primary, secondary, university I (3 years), and university II (5 years or more), and further recoded into 3-categories: primary, secondary and university. PA was estimated from questions about regular leisure time physical activities (aerobics, basketball, cycling, gymnastics, running, soccer, squash, swimming, tennis, volleyball, and others), as well as the average number of hours per week spent on each activity. According to the type and time, subjects were categorized as sedentary (no physical exercise), moderate ( 1 sport less than $3 \mathrm{~h} / \mathrm{wk}$ ) and high (1 sport more than $3 \mathrm{~h} /$ wk or more than 2 sports per week), as previously described [33]. For interaction analyses, PA was also dichotomized as sedentary versus active (moderate and high).

In the HCR subjects, socio-demographic factors and lifestyle variables were assessed at baseline as previously detailed [32]. Questions on educational level were also asked in the form of 5-answer options. They were then divided into three categories (primary, secondary and university). PA was estimated by the Minnesota Leisure Time Physical Activity questionnaire, in its version validated in Spain [32]. Thus the total amount of PA performed during the preceding year was assessed from a list of activities, and daily average energy expenditure in $\mathrm{Kcal} / \mathrm{d}$ was calculated. Population tertiles of total PA were considered ( $<106 \mathrm{kcal} / \mathrm{d}, 106-213 \mathrm{kcal} / \mathrm{d}$ and $>213 \mathrm{kcal} / \mathrm{d})$.

\section{DNA extraction and genotyping}

Genomic DNA was isolated from blood. The rs9939609 FTO SNP was determined in the same laboratory using a 7900HT Sequence Detection system (Applied Biosystems by Life Technologies) and a fluorescent allelic discrimination TaqMan assay by standard procedures. For quality control purposes, $10 \%$ of randomly selected samples were genotyped a second time, and there were no discrepancies. All populations were in Hardy-Weinberg equilibrium $(P=0.868$ for GP, $P=0.226$ for OHP and $P=0.348$ for HCR subjects).

\section{Statistical analysis}

$\chi^{2}$ tests were used to test differences in percentages. We applied analysis of variance and the $t$ tests to compare crude means. Co-dominant, dominant and recessive models were tested. Multivariate adjustment was undertaken by linear regression analysis. To study gene-environment interactions in determining BMI, we used multivariate linear regression models, including main effects and interaction terms. Regression coefficients and adjusted means for each predictor were estimated. Logistic regression models were fitted to estimate the odds ratio (OR) and $95 \%$ confidence intervals $(\mathrm{Cl})$ of obesity associated with the presence of each genetic variant as compared with the wild-type. Multiple logistic regression models were also fitted to control for the effect of covariates and effect modifiers as well as to test the interaction between the SNP and educational level and PA. Analyses were performed using the SPSS statistical software, version 17.0 (SPSS Inc, Chicago, Illinois). Significance was considered at the level of $P<0.05$.

\section{Results}

\section{Association between the FTO rs9939609 polymorphism and anthropometric variables}

General characteristics of the study subjects are shown in Table 1. GP subjects had a mean age $41.2 \pm 13.8 \mathrm{y}$ and BMI of $26.0 \pm 4.7 \mathrm{~kg} / \mathrm{m}^{2}$ (prevalence of obesity was $17.7 \%$ ). The mean age of OHP was slightly higher $(46.3 \pm 14.7 \mathrm{y})$ with a very high mean BMI $\left(41.8 \pm 8.4 \mathrm{~kg} / \mathrm{m}^{2}\right)$. The educational level of OHP was lower than that of the GP. In elderly HCR subjects mean BMI was $30.1 \pm 4.0 \mathrm{~kg} / \mathrm{m}^{2}$, with a high prevalence of obesity (49.1\%) and lower educational level than the GP.

We observed (Table 2) that the FTO SNP was strongly associated with greater weight, BMI and waist circumference in the GP. This association followed a co-dominant model, BMI increasing by +0.5 (SE: 0.2 ) units per risk-allele $(P=0.009)$. A greater prevalence of obesity was also observed when A-allele carriers were grouped and compared with TT subjects $(P=0.038)$. These results maintained statistical significant following adjustment for sex, age, smoking and diabetes. In OHP, the association of the FTO SNP with anthropometric measurements was recessive. No differences were observed between the TT and TA subjects, the presence of two A-alleles being necessary in order to observe higher differences in means. In HCR subjects no significant differences in means of weight, BMI and waist circumference depending on the FTO SNP were observed. 
Table 1 General characteristics of the studied samples.

\begin{tabular}{llll}
\hline & $\begin{array}{l}\text { General population } \\
(n=1,580)\end{array}$ & $\begin{array}{l}\text { Obese hospital subjects } \\
(n=203)\end{array}$ & $\begin{array}{l}\text { Elderly subjects HCR } \\
(n=1,027)\end{array}$ \\
\cline { 2 - 4 } & Mean (SD) & Mean (SD) & Mean (SD) \\
\hline Male/Female (n/n) & $757 / 823$ & $37 / 166$ & $325 / 582$ \\
Age (years) & $41.2(13.8)$ & $46.3(14.7)$ & $67.3(6.4)$ \\
Weight (Kg) & $71.2(14.2)$ & $108.6(23.1)$ & $76.0(11.4)$ \\
Height (m) & $1.7(0.1)$ & $1.6(0.1)$ & $1.6(0.1)$ \\
Waist (cm) & $91.4(14.4)$ & $119.7(17.2)$ & $103.1(11.5)$ \\
BMI (Kg/m $\left.{ }^{2}\right)$ & $26.0(4.7)$ & $41.8(8.4)$ & $30.1(4.0)$ \\
Obesity (\%) & 17.7 & 100.0 & 49.1 \\
Diabetes (\%) & 3.9 & 19.1 & 47.9 \\
Current smokers (\%) & 37.3 & 26.9 & 12.4 \\
Physical activity ${ }^{\text {; }}$ (\%) & & & \\
Sedentary/ First tertile (HCR) & 48.4 & 78.9 & 33.0 \\
Moderate/Second tertile (HCR) & 29.8 & 17.1 & 34.0 \\
High/ Third tertile (HCR) & 21.8 & 3.9 & 33.0 \\
Education (\%) & & & 82.4 \\
Primary & 47.1 & 73.3 & 10.7 \\
Secondary & 25.1 & 17.2 & 7.0 \\
University & 27.8 & 9.4 & 31.7 \\
FTO genotype (\%) & & 24.6 & 47.9 \\
TT & 34.7 & 54.2 & 20.4 \\
TA & 48.2 & 21.2 & \\
AA & 17.0 & &
\end{tabular}

HCR: High cardiovascular risk, SD: Standard deviation.

${ }^{a}$ Physical activity was measured by different questionnaires. In the general population and obese hospital patients, three categories (sedentary, moderate and high were considered). In HCR patients physical activity was estimated as continuous and three population tertiles were considered: First tertile $(<106 \mathrm{kcal} / \mathrm{d})$, second tertile $(106-213 \mathrm{kcal} / \mathrm{d})$ and third tertile $(>213 \mathrm{kcal} / \mathrm{d})$.

Table 2 Association of the FTO rs9939609 polymorphism with anthropometric variables in the three Mediterranean samples. Means by genotype and regression coefficients for the co-dominant model.

\begin{tabular}{|c|c|c|c|c|c|c|c|c|c|}
\hline & \multicolumn{3}{|c|}{ General population } & \multicolumn{3}{|c|}{ Obese hospital patients } & \multicolumn{3}{|l|}{ HCR subjects } \\
\hline & $\begin{array}{l}\text { TT } \\
(n=549)\end{array}$ & $\begin{array}{l}\text { TA } \\
(n=762)\end{array}$ & $\begin{array}{l}\mathrm{AA} \\
(n=269)\end{array}$ & $\begin{array}{l}\mathrm{TT} \\
(n=50)\end{array}$ & $\begin{array}{l}\text { TA } \\
(n=110)\end{array}$ & $\begin{array}{l}\mathrm{AA} \\
(n=43)\end{array}$ & $\begin{array}{l}\text { TT } \\
(n=326)\end{array}$ & $\begin{array}{l}\text { TA } \\
(n=492)\end{array}$ & $\begin{array}{l}\mathrm{AA} \\
(n=209)\end{array}$ \\
\hline & Mean (SD) & Mean (SD) & Mean (SD) & Mean (SD) & Mean (SD) & Mean (SD) & Mean (SD) & Mean (SD) & Mean (SD) \\
\hline \multirow[t]{5}{*}{ Weight (Kg) } & $69.9(14.2)$ & $71.2(13.7)$ & $73.9(15.2)$ & $108.4(21.8)$ & $105.4(19.4)$ & $116.8(30.6)$ & $76.6(11.7)$ & $75.4(11.1)$ & $76.5(11.6)$ \\
\hline & $\mathrm{B}(\mathrm{SE})$ & & & $B(S E)$ & & & $B(S E)$ & & \\
\hline & $1.8(0.5)$ & $P^{1}:<0.001$ & & $5.4(2.3)$ & $P^{1}: 0.077$ & & $0.3(0.6)$ & $P^{1}: 0.353$ & \\
\hline & & $P^{2}: 0.010$ & & & $P^{2}: 0.949$ & & & $P^{2}: 0.326$ & \\
\hline & & $P^{3}: 0.001$ & & & $P^{3}: 0.008$ & & & $P^{3}: 0.510$ & \\
\hline \multirow[t]{5}{*}{$\mathrm{BMI}\left(\mathrm{Kg} / \mathrm{m}^{2}\right)$} & $25.6(4.6)$ & $26.1(4.6)$ & $26.6(5.1)$ & $40.9(8.7)$ & $40.8(6.9)$ & $45.1(10.8)$ & $30.3(3.9)$ & $30.0(4.1)$ & $30.3(4.1)$ \\
\hline & $B(S E)$ & & & $B(S E)$ & & & $B(S E)$ & & \\
\hline & $0.5(0.2)$ & $P^{1}: 0.009$ & & $1.9(0.9)$ & $P^{1}: 0.020$ & & $0.2(0.2)$ & $P^{1}: 0.596$ & \\
\hline & & $P^{2}: 0.034$ & & & $P^{2}: 0.449$ & & & $P^{2}: 0.513$ & \\
\hline & & $P^{3}: 0.028$ & & & $P^{3}: 0.004$ & & & $P^{3}: 0.609$ & \\
\hline \multirow[t]{5}{*}{ Waist (cm) } & $89.4(14.5)$ & $91.9(14.3)$ & $93.7(14.3)$ & $118.9(19.4)$ & $118.4(15.5)$ & $123.9(18.0)$ & $103.2(12.1)$ & $102.5(11.2)$ & $104.1(10.9)$ \\
\hline & $\mathrm{B}(\mathrm{SE})$ & & & $\mathrm{B}(\mathrm{SE})$ & & & $\mathrm{B}(\mathrm{SE})$ & & \\
\hline & $2.2(0.8)$ & $P^{1}: 0.006$ & & $1.8(1.8)$ & $P^{1}: 0.196$ & & $0.9(1.2)$ & $P^{1}: 0.272$ & \\
\hline & & $P^{2}: 0.008$ & & & $P^{2}: 0.721$ & & & $P^{2}: 0.771$ & \\
\hline & & $P^{3}: 0.045$ & & & $P^{3}: 0.085$ & & & $P^{3}: 0.164$ & \\
\hline \multirow[t]{3}{*}{ Obesity $^{\mathrm{a}} ;(\%)$} & 14.9 & $\begin{array}{l}19.0 \\
P^{1}: 0.060\end{array}$ & 19.3 & 100 & $\begin{array}{l}100 \\
P^{1}:-\end{array}$ & 100 & 49.3 & $\begin{array}{l}52.3 \\
P^{1}: 0.380\end{array}$ & 46.5 \\
\hline & & $P^{2}: 0.038$ & & & $P^{2}:-$ & & & $P^{2}: 0.710$ & \\
\hline & & $P^{3}: 0.430$ & & & $P^{3}:-$ & & & $P^{3}: 0.257$ & \\
\hline
\end{tabular}

SD: Standard deviation; B: Regression coefficient for the corresponding variable per risk-allele (A) in the co-dominant model; SE: Standard error; $P^{1}: P$ value for difference of means according to a co-dominant model; $P^{2}: P$ value for difference of means according to a dominant model; $P^{3}: P$ value for difference of means according to a recessive model.

${ }^{\mathrm{a}} \mathrm{BMI}>=30 \mathrm{Kg} / \mathrm{m}^{2}$. 
Neither was any association with the prevalence of obesity found. The statistical significance of results did not change after multivariate adjustment for sex, age, smoking and diabetes. Further adjustment of these models for PA and education did not change the statistical significance of results.

\section{Interaction between the FTO SNP and education in determining $\mathrm{BMI}$ and obesity risk}

Firstly, we studied the interaction between educational level expressed in 3-categories and the FTO SNP in determining $\mathrm{BMI}$ in the GP (Fig. 1A). The interaction term between the FTO SNP and education did not reach the statistical significance $(P=0.152)$ when 3 -categories of educational level were considered. Thus, in the stratified analysis by educational level, we observed that the association between the A-allele and higher BMI in the GP was present in individuals with primary $(P=0.029)$ and secondary studies $(P=0.028)$, but not in university level subjects $(P=0.786)$. Hence, we decided to group primary and secondary studies together and to create a variable with 2-categories: non-university and university studies. This variable presented a statistically significant interaction term with the FTO SNP ( $P$ for interaction 0.048 ) in determining $\mathrm{BMI}$ in the GP (Fig. $1 \mathrm{~B})$. In OHP, this interaction was also studied, but no $A A$ individuals with university studies were found. OHP were analyzed jointly with the GP, introducing population origin as a covariate in the statistical model. Again, a statistically significant interaction term $(P=0.043)$ was obtained between the FTO SNP and educational level in determining BMI (Fig. 1C). In the stratified analysis, the FTO SNP was associated with higher $\mathrm{BMI}$ in non-university individuals $(P<0.001)$, but not in university level subjects $(P=0.760)$. In elderly subjects with HCR (Fig. 1D), no statistically significant interaction of education with the FTO SNP in determining BMI was detected ( $P$ for interaction 0.839 ). The statistical significance of the interactions terms did not change after additional adjustment of the corresponding models for PA. Moreover, we studied the interaction between the FTO SNP and PA on BMI (Supplementary Fig. S1) and did not observe any significant interaction term between PA levels (sedentary versus active) and the FTO SNP in determining BMI in the GP $(P=0.617)$. However, in HCR subjects, we found a statistically significant interaction term $(P=0.045)$ when we considered the first tertile of PA (sedentary) versus the others. The statistical significance of the interaction terms between education and the FTO SNP did not change after additional adjustment for the interaction between FTO and PA (not shown).

In terms of obesity, we found a clear inverse association between education and obesity risk in the GP (Table 3). Subjects with university education had a lower obesity risk
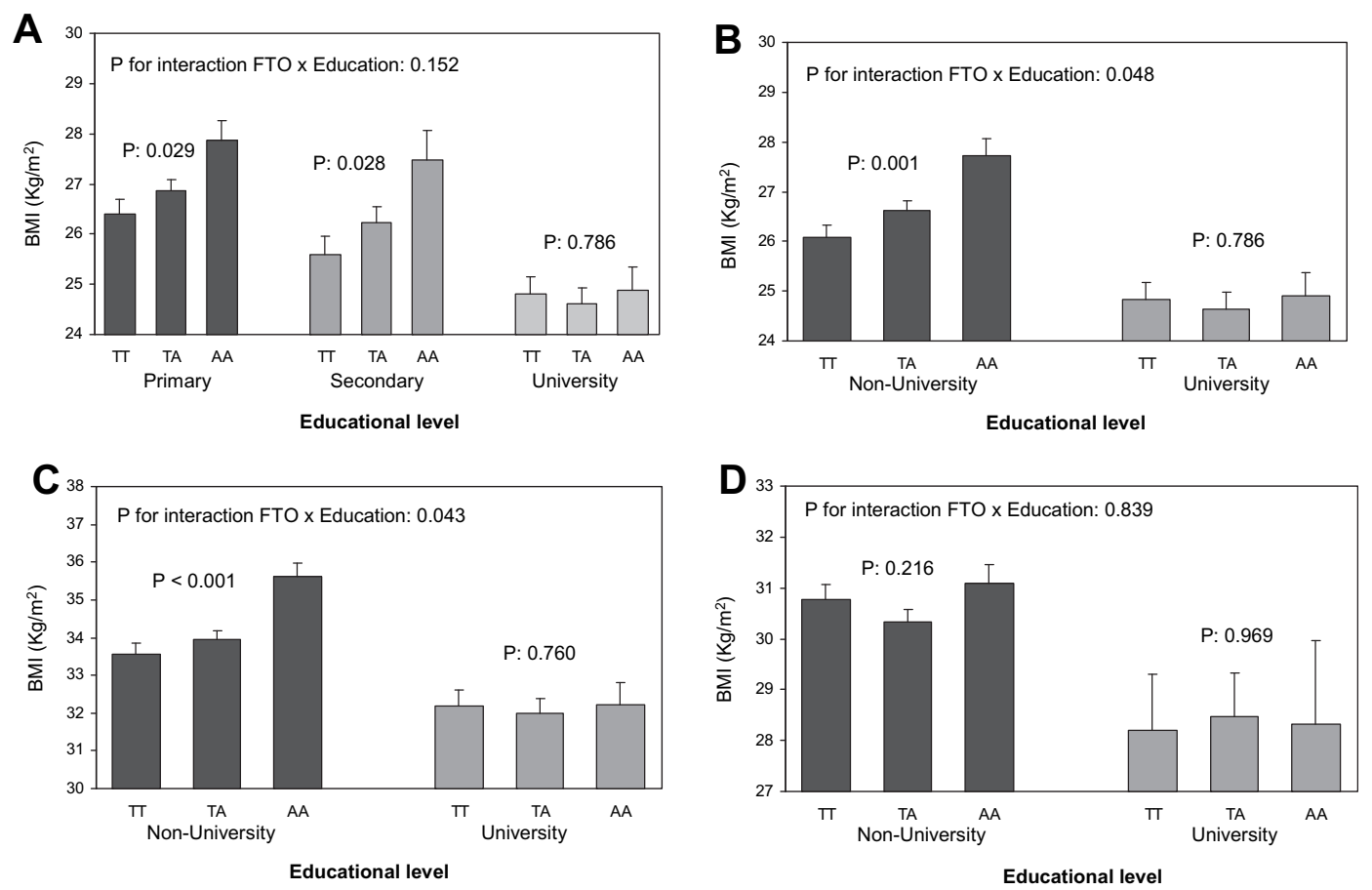

Figure 1 Adjusted means of BMI in subjects from the Mediterranean population depending on the educational level and the rs9939609 FTO polymorphism (3-categories, primary, secondary and university) in: (A) general population and educational level expressed as a 3-categories variable $(n=1580)$; (B) general population $(n=1580)$ and educational level expressed as a 2 categories variable (non-university versus university level); (C) obese hospital patients analyzed jointly with the general population ( $n=1783)$; (D) elderly subjects with high cardiovascular risk $(n=1027)$. Models were adjusted for sex, age and origin of the sample. $P$ values for the interaction terms between education categories and the rs 9939609 FTO polymorphism (3-categories) were estimated in the multivariate adjusted model. $P$ values for mean comparison in each education stratum were also adjusted for the same covariates. Additional adjustment for smoking, diabetes or physical activity did not change the statistical significance of the interactions. Bar: SE of means. 
Table 3 Odds ratios for obesity by educational level and the FTO rs9939609 in the GP and stratified analysis of the association of the FTO SNP depending on education in the GP and in the joint analysis including obese hospital subjects.

\begin{tabular}{|c|c|c|c|c|}
\hline Strata & Variable $^{a}$ & OR & $95 \% \mathrm{Cl}$ & $P$ \\
\hline \multicolumn{5}{|c|}{ General population $(n=1580)$} \\
\hline \multirow[t]{8}{*}{ Whole population } & Educational level & & & $<0.001$ \\
\hline & Primary & 1 & & \\
\hline & Secondary & 0.63 & $(0.44-0.88)$ & 0.007 \\
\hline & University & 0.37 & $(0.25-0.54)$ & $<0.001$ \\
\hline & FTO rs9939609 & & & 0.077 \\
\hline & $\mathrm{TT}$ & 1 & & \\
\hline & TA & 1.30 & $(0.94-1.81)$ & 0.112 \\
\hline & AA & 1.60 & $(1.05-2.43)$ & 0.030 \\
\hline \multicolumn{5}{|c|}{ Stratified by Education level } \\
\hline \multirow[t]{4}{*}{ Non-University level } & FTO rs9939609 & & & 0.007 \\
\hline & TT & 1 & & \\
\hline & TA & 1.56 & $(1.09-2.23)$ & 0.016 \\
\hline & AA & 2.01 & $(1.27-3.26)$ & 0.003 \\
\hline \multirow[t]{4}{*}{ University level } & FTO rs9939609 & & & 0.149 \\
\hline & $\mathrm{TT}$ & 1 & & \\
\hline & TA & 0.47 & $(0.20-1.10)$ & 0.079 \\
\hline & $\mathrm{AA}$ & 0.46 & $(0.16-1.38)$ & 0.166 \\
\hline \multicolumn{5}{|c|}{ General population plus obese hospital subjects $(n=1783)$} \\
\hline \multicolumn{5}{|c|}{ Stratified by Education level } \\
\hline \multirow[t]{4}{*}{ Non-University level } & FTO rs9939609 & & & 0.009 \\
\hline & $\mathrm{TT}$ & 1 & & \\
\hline & TA & 1.55 & $(1.08-2.22)$ & 0.018 \\
\hline & AA & 1.97 & $(1.24-3.14)$ & 0.005 \\
\hline \multirow[t]{4}{*}{ University level } & FTO rs9939609 & & & 0.146 \\
\hline & $\mathrm{TT}$ & 1 & & \\
\hline & TA & 0.46 & $(0.19-1.09)$ & 0.079 \\
\hline & AA & 0.46 & $(0.15-1.37)$ & 0.164 \\
\hline
\end{tabular}

OR: Odds ratio; $\mathrm{Cl}$ : Confidence Interval.

${ }^{a}$ Logistic regression models were additionally adjusted for sex, age and population.

(OR: $0.37 ; 95 \% \mathrm{Cl}: 0.25-0.54$ ) than did subjects with primary studies. Likewise, AA subjects had a higher obesity risk than TT homozygotes. No significant association was found for TA subjects in the whole population. On analyzing the interaction term between the FTO SNP and education, we found a statistically significant interaction ( $P$ for interaction: 0.020) in determining obesity in the GP. In the stratified analysis by educational level in the GP we observed that in individuals without university studies, then FTO SNP was associated with higher obesity risk both in TA (OR: 1.56; 95\% $\mathrm{Cl}: 1.09-2.23$ ) and in AA subjects (OR: 2.01; $95 \% \mathrm{Cl}$ : 1.27-3.26). However, in individuals with university studies, no significant associations between the FTO SNP and obesity risk were found, and even a change in the direction of the effect associated with the A-allele was detected. In the joint analysis of both the GP and OHP, we also observed a statistically significant interaction term between education and the FTO SNP in determining obesity risk ( $P$ for interaction $=0.023$ ). No significant interaction was obtained in the HCR subjects $(P=0.957$ for the interaction term between the FTO SNP and education). The statistical significance of these estimations did not change after additional adjustment for PA (not shown).

\section{Discussion}

In this study, carried out on 3 independent samples of the Mediterranean population, we have observed that the association between the FTO SNP and BMI is heterogeneous, depending on the characteristics of the sample and has an important modulation by education. In the GP, we have found a strong association of the A-allele with greater $\mathrm{BMI}$, following a co-dominant model. In the OHP with a high percentage of morbid obesity, the FTO SNP has also been significantly associated with greater BMI, following a recessive model. However, in the elderly population no significant association was observed.

The FTO has been associated with obesity in numerous, but not all [19-21] populations; however, the magnitude of the association varies depending on the sample and the ethnical background [14-18,22-24]. The lack of significant association seen in the sample of elderly subjects finds support in a previous study carried out in the MRC National Survey of Health and Development [22] which has shown that the association of the FTO SNP on BMI diminishes with age. Likewise, Qi et al. [23], also observed a lesser association of the FTO SNP in elderly women. In addition to the age influence, other environmental variables could be 
having an important influence on the attenuation of the FTO association. Among these environmental variables, some significant interactions have been reported for PA [24-26]. However, we have not found a significant interaction with PA in the GP in determining BMI. In the elderly population, we did find a weak interaction. One limitation of our work is that PA has been measured through questionnaires instead of directly employing objective measurements. This may have led to a misclassification of the amount of PA undertaken and could have an influence on the results obtained.

Interestingly, we did find a statistically significant interaction between the FTO SNP and education. As far as we know, this is the first time that a significant interaction between the FTO SNP and educational level in determining $\mathrm{BMI}$ and obesity is reported. The statistical significance of this interaction remains when the GP and OHP samples are included in a joint analysis. Although there is ample evidence that educational level is an important environmental variable associated with obesity and cardiovascular risk [1-7], there have been scarcely any studies that have examined the interaction of this variable with the effects of genetic variability in determining BMI [11-13], the exception being a recent publication by Holzapfel et al. [34], that investigates the association between SNPs in the TMEM18 and FTO genes with educational level as well as income; however, the authors did not formally analyze the interaction between these SNPs and education in determining BMI and obesity, and we cannot compare our results with theirs [34].

Our findings in the GP could be explained by the fact that a higher level of education is normally accompanied by a series of healthier lifestyles [6-9]. These lifestyles may mask the greater genetic susceptibility to increased weight in susceptible individuals. This less obesogenic lifestyle would not include only PA, but also diet, free time activities, stress, sleeping patterns and other variables associated with higher education.

In our elderly population, the interaction term with educational level did not reach statistical significance, possibly due to the low number of subjects with university education. However, as result of the different age mean between the GP and the elderly population, other factors related to the characteristics of the Spanish society in different generations could have an influence. Most individuals in the elderly cohort were born in the period following the Spanish Civil War (ended in 1939), when food was very scarce. This great scarcity of food may have masked the genetic effects of the A-allele, in contrast to what would be expected in a situation of greater food availability, as in later generations which are those that most make up the majority GP sample. Regarding this historical fact, a lower educational level in our elderly population used to be associated with higher level of PA as they had to do work harder, whereas a higher educational level would allow one to enjoy a more comfortable situation with more sedentary work and greater food intake. Later, this situation was reversed and currently greater food intake and sedentarism are detected in subjects with lower education.

In conclusion, we have detected heterogeneity in the association of the FTO SNP with anthropometric measurements depending on the characteristics of the sample even within a single geographical area and ethnicity. Moreover, our most important result has been the finding of an interaction between educational level and FTO SNP. Despite the important associations of the FTO SNP with anthropometric measurements in the GP, this association was not present in subjects of university education, so indicating that, although there is a certain degree of genetic susceptibility to greater weight conferred by the A-allele, subjects with higher educational level are capable of undertaking a series of lifestyle behaviours that would consist not only of more PA, but also in a series of healthier conducts that could minimize the impact of the obesogenic environment and neutralize the influence of that strong genetic susceptibility.

\section{Acknowledgements}

This work was supported by grants from the Ministerio de Ciencia e Innovación (CIBER CB06/03/0035, RD07/0067/ 0006, PI06-1326, PI07-0954, PI08-90002 and SAF-09-12304), the Generalitat Valenciana (GVACOMP2010-181, BEST2010211, BEST2010-032) and the National Heart, Lung, and Blood Institute grants HL-54776, National Institute of Diabetes and Digestive and Kidney Diseases, Grant Number DK075030 and by contracts 53-K06-5-10 and 58-1950-9-001 from the US Department of Agriculture Research.

\section{Appendix \\ Supplementary data}

Supplementary data related to this article can be found online at doi:10.1016/j.numecd.2010.10.006.

\section{References}

[1] Garrison RJ, Gold RS, Wilson PW, Kannel WB. Educational attainment and coronary heart disease risk: the Framingham offspring study. Prev Med 1993;22:54-64.

[2] Nanchahal K, Morris JN, Sullivan LM, Wilson PW. Coronary heart disease risk in men and the epidemic of overweight and obesity. Int J Obes (Lond) 2005;29:317-23.

[3] Karlamangla AS, Merkin SS, Crimmins EM, Seeman TE. Socioeconomic and ethnic disparities in cardiovascular risk in the United States, 2001-2006. Ann Epidemiol 2010;20:617-28.

[4] Singh GK, Siahpush M, Hiatt RA, Timsina LR. Dramatic increases in obesity and overweight prevalence and body mass index among ethnic-immigrant and social class groups in the United States, 1976-2008. J Community Health in press, doi: 10.1007/s10900-010-9287-9.

[5] Marques-Vidal P, Bovet P, Paccaud F, Chiolero A. Changes of overweight and obesity in the adult Swiss population according to educational level, from 1992 to 2007. BMC Public Health 2010;10:87.

[6] Rodríguez-Martín A, Novalbos Ruiz JP, Martínez Nieto JM, Escobar Jiménez L. Life-style factors associated with overweight and obesity among Spanish adults. Nutr Hosp 2009;24: 144-51.

[7] Roskam AJ, Kunst AE, Van Oyen H, Demarest S, Klumbiene J, Regidor E, et al. Comparative appraisal of educational inequalities in overweight and obesity among adults in 19 European countries. Int J Epidemiol 2010;39:392-404.

[8] Deshmukh-Taskar P, Nicklas TA, Yang SJ, Berenson GS. Does food group consumption vary by differences in socioeconomic, 
demographic, and lifestyle factors in young adults? The Bogalusa heart study. J Am Diet Assoc 2007;107:223-34.

[9] Nyholm M, Gullberg B, Haglund B, Råstam L, Lindblad U. Higher education and more physical activity limit the development of obesity in a Swedish rural population. The Skaraborg project. Int J Obes (Lond) 2008;32:533-40.

[10] Hemphill E, Raine K, Spence JC, Smoyer-Tomic KE. Exploring obesogenic food environments in Edmonton, Canada: the association between socioeconomic factors and fast-food outlet access. Am J Health Promot 2008;22:426-32.

[11] Silventoinen K, Sarlio-Lähteenkorva S, Koskenvuo M, Lahelma E, Kaprio J. Effect of environmental and genetic factors on education-associated disparities in weight and weight gain: a study of Finnish adult twins. Am J Clin Nutr 2004;80:815-22.

[12] Johnson W, Kyvik KO, Mortensen EL, Skytthe A, Batty GD, Deary IJ. Education reduces the effects of genetic susceptibilities to poor physical health. Int J Epidemiol 2010;39:406-14.

[13] Pigeyre M, Bokor S, Romon M, Gottrand F, Gilbert CC, Valtueña J, et al. Influence of maternal educational level on the association between the rs3809508 neuromedin B gene polymorphism and the risk of obesity in the HELENA study. Int J Obes (Lond) 2010;34:478-86.

[14] Frayling TM, Timpson NJ, Weedon MN, Zeggini E, Freathy RM, Lindgren $C M$, et al. A common variant in the FTO gene is associated with body mass index and predisposes to childhood and adult obesity. Science 2007;316:889-94.

[15] Dina C, Meyre D, Gallina S, Durand E, Körner A, Jacobson P, et al. Variation in FTO contributes to childhood obesity and severe adult obesity. Nat Genet 2007;39:724-6.

[16] Scuteri A, Sanna S, Chen WM, Uda M, Albai G, Strait J, et al. Genome-wide association scan shows genetic variants in the FTO gene are associated with obesity-related traits. PLOS Genet 2007;3:e115.

[17] Hotta K, Nakata Y, Matsuo T, Kamohara S, Kotani K, Komatsu R, et al. Variations in the FTO gene are associated with severe obesity in the Japanese. J Hum Genet 2008;53:546-53.

[18] Tan JT, Dorajoo R, Seielstad M, Sim XL, Ong RT, Chia KS, et al. FTO variants are associated with obesity in the Chinese and Malay populations in Singapore. Diabetes 2008;57:2851-7.

[19] Jacobsson JA, Risérus U, Axelsson T, Lannfelt L, Schiöth HB, Fredriksson R. The common FTO variant rs9939609 is not associated with BMI in a longitudinal study on a cohort of Swedish men born 1920-1924. BMC Med Genet 2009;10:131.

[20] Hennig BJ, Fulford AJ, Sirugo G, Rayco-Solon P, Hattersley AT, Frayling TM, et al. FTO gene variation and measures of body mass in an African population. BMC Med Genet 2009;10:21.

[21] Ohashi J, Naka I, Kimura R, Natsuhara K, Yamauchi T, Furusawa T, et al. FTO polymorphisms in oceanic populations. J Hum Genet 2007;52:1031-5.

[22] Hardy R, Wills AK, Wong A, Elks CE, Wareham NJ, Loos RJ, et al. Life course variations in the associations between FTO and MC4R gene variants and body size. Hum Mol Genet 2010;19:545-52.

[23] Qi L, Kang K, Zhang C, van Dam RM, Kraft P, Hunter D, et al. Fat mass-and obesity-associated (FTO) gene variant is associated with obesity: longitudinal analyses in two cohort studies and functional test. Diabetes 2008;57:3145-51.

[24] Xi B, Shen Y, Zhang M, Liu X, Zhao X, Wu L, et al. The common rs 9939609 variant of the fat mass and obesity-associated gene is associated with obesity risk in children and adolescents of Beijing, China. BMC Med Genet 2010;11:107.

[25] Rampersaud E, Mitchell BD, Pollin TI, Fu M, Shen $H$, O'Connell JR, et al. Physical activity and the association of common FTO gene variants with body mass index and obesity. Arch Intern Med 2008;168:1791-7.

[26] Ruiz JR, Labayen I, Ortega FB, Legry V, Moreno LA, Dallongeville J, et al. Attenuation of the effect of the FTO rs9939609 polymorphism on total and central body fat by physical activity in adolescents: the HELENA study. Arch Pediatr Adolesc Med 2010;164:328-33.

[27] Jonsson A, Renström F, Lyssenko V, Brito EC, Isomaa B, Berglund $G$, et al. Assessing the effect of interaction between an FTO variant (rs9939609) and physical activity on obesity in 15,925 Swedish and 2511 Finnish adults. Diabetologia 2009;52:1334-8.

[28] Liu G, Zhu H, Lagou V, Gutin B, Stallmann-Jorgensen IS, Treiber FA, et al. FTO variant rs9939609 is associated with body mass index and waist circumference, but not with energy intake or physical activity in European- and African- American youth. BMC Med Genet 2010;11:57.

[29] Tzormpatzakis N, Sleap M. Participation in physical activity and exercise in Greece: a systematic literature review. Int J Public Health 2007;52:360-71.

[30] Qi L, Corella D, Sorlí JV, Portolés O, Shen H, Coltell O, et al. Genetic variation at the perilipin (PLIN) locus is associated with obesity-related phenotypes in White women. Clin Genet 2004;66:299-310.

[31] Corella D, Qi L, Sorlí JV, Godoy D, Portolés O, Coltell O, et al. Obese subjects carrying the $11482 \mathrm{G}>\mathrm{A}$ polymorphism at the perilipin locus are resistant to weight loss after dietary energy restriction $>$ A polymorphism at the perilipin locus are resistant to weight loss after dietary energy restriction. J Clin Endocrinol Metab 2005;90:5121-6.

[32] Estruch R, Martínez-González MA, Corella D, Salas-Salvadó J, Ruiz-Gutiérrez V, Covas MI, et al. Effects of a Mediterraneanstyle diet on cardiovascular risk factors: a randomized trial. Ann Intern Med 2006;145:1-11.

[33] Corella D, Guillén M, Sáiz C, Portolés O, Sabater A, Cortina S, et al. Environmental factors modulate the effect of the APOE genetic polymorphism on plasma lipid concentrations: ecogenetic studies in a Mediterranean Spanish population. Metabolism 2001;50:936-44.

[34] Holzapfel C, Grallert H, Baumert J, Thorand B, Döring A, Wichmann HE, et al. First investigation of two obesity-related loci (TMEM18, FTO) concerning their association with educational level as well as income: the MONICA/KORA study. J Epidemiol Community Health in press, Published Online First: 13 July 2010. 